\title{
EFFECTS OF AGE AND GENDER IN PHYSIOLOGICAL RESPONSES, MECHANICS, AND PERFORMANCE OF MASTER SWIMMERS
}

original paper

( ) University School of Physical Education in Wroclaw

DOI: https://doi.org/10.5114/hm.2019.79393

\section{VASILIKI LAMPADARI ${ }^{1}$, VASSILEIOS THANOPOULOS ${ }^{1}$, MILIVOJ DOPSAJ ${ }^{2}$, GEORGIA ROZI ${ }^{1}$}

${ }^{1}$ Department of Aquatics, Faculty of Physical Education and Sports Science, National and Kapodistrian University of Athens, Athens, Greece

${ }^{2}$ Department of Theory and Technology of Sports Training Science Analysis and Diagnosis in Sport, Faculty of Sports and Physical Education, University of Belgrade, Belgrade, Serbia

\section{ABSTRACT}

Purpose. The purpose of the study was to analyse the effects of age and gender in physiological responses, mechanics (stroke frequency, stroke length, stroke index), and performance time of master swimmers.

Methods. Overall, 34 male and 25 female master swimmers were divided into 2 age categories: (a) 30-39 years, (b) 40-49 years, and completed a 100-m freestyle swimming test with maximum intensity. Stroke mechanics and performance time were measured during the effort. Blood lactate concentration was determined after the test in the $3^{\text {rd }}$, $5^{\text {th }}$, and $10^{\text {th }}$ minutes of passive recovery.

Results. Two-way ANOVA showed no interaction between gender and age category for any examined variable $(p>0.05)$. Maximum blood lactate was maintained in both genders despite ageing $(p>0.05)$ and was lower for females compared with males $(p<0.001)$. Higher values were observed for stroke frequency, stroke length, and stroke index for males $(p<0.05)$. For both genders, the 30-39 years category had significantly higher values for stroke length $(p=0.020)$ and lower for stroke frequency $(p=0.014)$, indicating that these swimmers can produce stronger strokes than those in the 40-49 years category. Performance time values were significantly lower for males compared with females $(p<0.001)$, but did not change with ageing $(p>0.05)$. Conclusions. Despite ageing, swimmers are able to maintain all examined variables through a structured swimming training but with a possible decrease in stroke mechanics, independent of gender. Better values were observed for males compared with females probably owing to a greater muscle mass in the former.

Key words: master swimming, blood lactate, stroke, time performance

\section{Introduction}

A variety of sports, with running, cycling, and swimming most popular, are widespread among master athletes. As part of master sports, competitive or recreational swimming offers improvements in physical and mental health [1] independent of previous experience in the sport [2].

Ageing in sedentary population results in a decrement of HRpeak and oxygen consumption, high blood pressure, and failure to fulfil aerobic and anaerobic tasks [3]. Muscle mass and muscle fibre type and size are strongly affected [4] and during ageing this population suffers from morbidity, mortality, lack of independence, and a decrease in the quality of life [5]. The previously sedentary population interested in master swimming should be investigated carefully, especially those wishing competitive participation, with the consideration of the fact that they were not formerly competitive athletes. A long term training plan for the abovementioned master swimmers should account for specific physiological and mechanical changes that occur with ageing [3].

Studies referring to maximum blood lactate con-

Correspondence address: Vasiliki Lampadari, Department of Aquatics, Faculty of Physical Education and Sports Science, National and Kapodistrian University of Athens, Ethnikis Antistasis 41, Dafni, 17237, Athens, Greece, e-mail: vlampadari@phed.uoa.gr

Received: August 28, 2018

Accepted for publication: October 23, 2018

Citation: Lampadari V, Thanopoulos V, Dopsaj M, Rozi G. Effects of age and gender in physiological responses, mechanics, and performance of master swimmers. Hum Mov. 2019;20(1):17-23; doi: https://doi.org/10.5114/hm.2019.79393. 


\section{HUMAN MOVEMENT}

V. Lampadari, V. Thanopoulos, M. Dopsaj, G. Rozi, Ageing and gender in master swimmers

centration (LAmax) of master swimmers are scarce. Despite ageing, LAmax remains stable in male subjects following high-intensity training [6], or it may decrease in both genders over a season of a structured swimming training combined with performance improvement [7]. However, differences of LAmax between genders are not well studied. Time to reach LAmax (tLAmax) may not be related to the ageing process [6].

Previous findings claim that performance time increases with ageing [8-11]. After ca. 35-40 years of age, performance decrement is linear, about $1 \%$ per year, and becomes exponential after the age of $70[8,9]$. The decrement is probably attributed to reductions of physiological functions or even psychological or social environment factors, injuries, or reduction of training load [8,9]. On the other hand, most recent studies indicate that performance time can be maintained or even improved through structured training up to a certain age [7, 12-14]. Such training design refers to highintensity or high-volume training. Gender differences reveal a similar rate of decline due to ageing but better performances for males compared with females of the same age categories, probably owing to a greater muscle mass in men [15].

Positive links between stroke characteristics improvement and performance time decrease have been reported by Ferreira et al. [16], who indicate that performance strongly connects to stroke mechanics [17]. As a result, possible strength and power loses owing to ageing might affect stroke mechanics and performance.

Obtaining information concerning blood lactate parameters, stroke mechanics, and performance time during ageing will provide significant data regarding the progress of the athlete, and possible decrements due to ageing, allowing to set goals and design an appropriate training plan.

The aim of the present study is to investigate physiological responses, mechanical swimming characteristics, and performance of maximal swimming effort in master swimmers of different age groups and genders.

\section{Material and methods}

\section{Participants}

The total of 59 healthy master swimmers were recruited from various athletic clubs of the same suburbs and volunteered to participate in the study. The swimmers were divided into 10-year-range age groups [6, 18]: (a) 30-39 years of age (females: $n=13$, males: $n=19$ ); (b) 40-49 years of age (females: $n=12$, males: $n=15$ ).

The subjects were non-smokers, had at least 1 year of swimming experience, and avoided any other physical activity for 6 months prior to participation. They were instructed to maintain their normal diet, avoid any strenuous exercises, and abstain from any alcohol consumption for 1 week prior to the test. The descriptive statistics for age, height, and body mass are presented in Table 1.

\section{Design and procedures}

The present study analysed the effects of ageing and gender on physiological responses, swimming stroke mechanics, and performance of master swimmers aged 30-49 years.

The training program logs, available from the coaches of the swimmers, presented that all swimmers were involved in a 60-min training program of 3 sessions per week the year before the measurement. Each swimming session was supervised by a swimming coach. Aerobic and anaerobic sets were involved in the training program as $63 \pm 3 \%$ and $12 \pm 4 \%$ of the training volume, respectively, and were calculated from the mean values of training program logs for each week of the year for all the participants. The other $25 \pm 2 \%$ involved warm-up and recovery. Drill sets and swimming equipment (fins, paddles) were used in order to improve the technique parameters and muscular strength. The training volume and intensity were not characterized as high but medium, compared with other studies of master swimmers [12]. All swimmers were considered as fitness swimmers since some of them used to participate in local

Table 1 . Mean $\pm S D$ values regarding age, body height, and body mass in both genders and age categories

\begin{tabular}{lrrrr}
\hline \multirow{2}{*}{$\begin{array}{l}\text { Anthropometric } \\
\text { characteristics }\end{array}$} & \multicolumn{3}{c}{ Females } & \multicolumn{2}{c}{ Males } \\
\cline { 2 - 5 } & $30-39$ years & $40-49$ years & 30-39 years & $40-49$ years \\
\hline Age (years) & $34.7 \pm 2.5$ & $44.7 \pm 3.6$ & $33.5 \pm 2.9$ & $45.1 \pm 2.5$ \\
Body height (cm) & $165.5 \pm 7.3$ & $164.9 \pm 6.7$ & $182.8 \pm 7.6$ & $177.1 \pm 8.1$ \\
Body mass (kg) & $56.4 \pm 6.6$ & $59.9 \pm 9.3$ & $82.8 \pm 9.5$ & $81.5 \pm 14.0$ \\
\hline
\end{tabular}


master swimming events once or twice per year and the general purpose of exercising was fitness and recreation as described by Lucero and Bleul-Gohlke [2].

\section{Measurements}

Measurements were conducted in an indoor 25-m swimming pool $\left(26-27^{\circ} \mathrm{C}\right)$ during-afternoon hours. Before the test, anthropometric characteristics were obtained and the participants completed a questionnaire indicating previous training experience and competitive participation. Prior to the test, all swimmers performed a 15-min self-paced warm-up. After 10 minutes of rest, each individual was instructed to complete a 100-m freestyle swimming test with maximum intensity.

In order to eliminate the influence of the dive, a wallpush start and a wall-grab turn on the surface level were applied. All individuals managed to swim under the international swimming rules of the Fédération Internationale de Natation (FINA).

Performance time was determined for the whole distance (T100) with a stopwatch (Seiko S141; Japan) by 2 experienced researchers and the mean value was used for the analysis. Stroke frequency (SF) was measured by 2 experienced researchers with a crono-frequency meter (Golfinho Sports MC 815; Aveiro, Portugal) from 3 consecutive stroke cycles in the middle of each lap and the mean value of all laps was used for the analysis. One stroke cycle was defined as the full movement cycle of one arm. Stroke length (SL) was calculated as the quotient of speed vs. SF [19]. Stroke index (SI) as an indicator of swimming efficiency was established by the product of speed and SL as suggested by Costill et al. [20].

In order to determine swimming intensity, maximum heart rate (HRpeak) was measured with a Polar heart rate monitor (Polar S610 Electro; Kempele, Finland) placed on the sternum, immediately after the test. Estimated maximum heart rate (HRmax) was calculated in accordance with Tanaka et al. [21], with the following equation:

$$
\text { HRmax }=208-0.7^{*} \text { age }
$$

Lactate concentration measurement was conducted at the $3^{\text {rd }}, 5^{\text {th }}$, and $10^{\text {th }}$ minute of passive recovery [22] after the T100 while the individual was sitting on a comfortable chair out of the water. In each measurement, a blood sample was taken from the tip of the finger and analysed with a Lactate Scout analyser (SensLab, Germany). LAmax was considered to be the highest blood lactate concentration in post-exercise condition. After the measurements, tLAmax was calculated.

\section{Statistical analysis}

Data are displayed as means $\pm S D$. All statistical tests were processed with the use of the SPSS statistical package (v. 25, IBM SPSS Inc.; Chicago, USA). The normality of the distributions was determined with the Shapiro-Wilk test. Standard statistical methods were used for the calculation of the means and standard deviations. Two-way analysis of variance (ANOVA) was applied in order to assess the effects of gender and age category ( 2 gender groups [males and females] $\times$ 2 groups of age categories [30-39 and 40-49 years]) on the dependent variables of LAmax, tLAmax, SF, SL, SI, T100, and years of swimming experience. The difference between HRpeak and HRmax was analysed with a three-way repeated measures ANOVA $\left(1^{\text {st }}\right.$ independent factor: age; $2^{\text {nd }}$ independent factor: gender; $3^{\text {rd }}$ repeated measures factor: heart rate [max vs. peak]). Eta squared $\left(\eta^{2}\right)$ effect sizes were calculated as the sums of squares for the effect of interest divided by the total sums of squares [23]. The small, medium, and large effects were reflected in values greater than 0.01, 0.06, and 0.14, respectively [23]. Significance was accepted at the $p<0.05$ level.

\section{Ethical approval}

The research related to human use has been complied with all the relevant national regulations and institutional policies, has followed the tenets of the Declaration of Helsinki, and has been approved by the authors' institutional review board.

\section{Informed consent}

Informed consent has been obtained from all individuals included in this study. The form involved information about the procedures of the experiment and the right to withdraw at any time.

\section{Results}

Years of swimming experience showed no interaction between the 2 examined factors of age category or gender $\left(F_{1,55}=0.69, p=0.409\right)$. Moreover, no difference in years of swimming experience was observed between genders or age category (females: $4.5 \pm 2.92$ vs. males: $3.76 \pm 3.41$ years, $F_{1,55}=0.77, p=0.38$; 30-39 category: $3.52 \pm 3.34$ vs. $40-49$ category: $4.74 \pm$ 2.95 years, $F_{1,55}=2.38, p=0.13$ ). 


\section{HUMAN MOVEMENT}

V. Lampadari, V. Thanopoulos, M. Dopsaj, G. Rozi, Ageing and gender in master swimmers

Blood lactate

The results of the two-way ANOVA failed to reveal interaction between the 2 factors (gender and age category) for LAmax $\left(F_{1,55}=2.07, p=0.156\right)$ or tLAmax $\left(F_{1,55}=0.61, p=0.439\right)$. The results for LAmax and tLAmax for the independent variable of gender are presented in Table 2 and for age category in Table 3.

\section{Mechanics}

No significant interaction was detected between the 2 factors (gender or age category) for $\mathrm{SF}\left(F_{1,55}=\right.$ $0.11, p=0.739)$, SL $\left(F_{1,55}=0.01, p=0.930\right)$, or SI $\left(F_{1,55}=0.03, p=0.854\right)$. The results for SF, SL, and SI for the independent variable of gender are presented in Table 2 and for age category in Table 3.

\section{Performance}

No interaction between gender and age category could be demonstrated for the variable of T100 $\left(F_{1,55}\right.$ $=0.32, p=0.577)$. The results for $\mathrm{T} 100$ for the independent variable of gender are presented in Table 2 and for age category in Table 3.

\section{Heart rate}

HRpeak was different from HRmax for the whole sample $(172.88 \pm 12.38$ and $180.71 \pm 4.32$ beats/ min, respectively, $F_{1,55}=20.08, \eta^{2}=0.22$ [large effect], $p<0.001$ ). HRpeak was different from HRmax for gender (females: $180.36 \pm 4.14$ and $178.32 \pm 9.41$ beats/min; males: $180.97 \pm 4.49$ and $168.8 \pm 12.89$ beats $/ \mathrm{min}, F_{1,55}=10.27, \eta^{2}=0.11$ [medium effect], $p=$ 0.002 , respectively) and age category (30-39 category: $184.2 \pm 1.95$ and $173.25 \pm 12.5$ beats $/ \mathrm{min}$; 40-49 category: $176.58 \pm 2.09$ and $172.44 \pm 12.41$ beats $/ \mathrm{min}$,

Table 2. Mean $\pm S D$ values, $F$ results, $p$ values, and effect sizes $\left(\eta^{2}\right)$ for T100, SF, SL, SI, LAmax, and tLAmax in both genders

\begin{tabular}{|c|c|c|c|c|c|c|c|}
\hline \multirow{2}{*}{ Variables } & \multicolumn{2}{|c|}{ Females } & \multicolumn{2}{|c|}{ Males } & \multirow{2}{*}{$F_{1,55}$} & \multirow{2}{*}{$p$ value } & \multirow{2}{*}{$\eta^{2}$} \\
\hline & Mean & $S D$ & Mean & $S D$ & & & \\
\hline T100 (s) & 126.79 & 22.65 & 105.37 & 20.52 & 13.59 & $<0.001^{*}$ & 0.20 \\
\hline $\mathrm{SF}\left(\right.$ cycle $\left.\cdot \min ^{-1}\right)$ & 28.14 & 4.77 & 30.51 & 4.70 & 4.13 & $0.047^{*}$ & 0.06 \\
\hline $\mathrm{SL}\left(\mathrm{m} \cdot \mathrm{cycle}^{-1}\right)$ & 1.75 & 0.28 & 1.97 & 0.38 & 4.91 & $0.031^{*}$ & 0.07 \\
\hline SI $\left[\mathrm{m}^{2} \cdot(\text { cycle } \cdot \mathrm{s})^{-1}\right]$ & 1.45 & 0.46 & 1.98 & 0.72 & 9.90 & $<0.001 *$ & 0.15 \\
\hline $\operatorname{LAmax}\left(\mathrm{mmol} \cdot \mathrm{l}^{-1}\right)$ & 8.83 & 3.08 & 11.72 & 3.37 & 11.96 & $<0.001^{*}$ & 0.17 \\
\hline tLAmax (s) & 282.24 & 121.47 & 280.03 & 132.88 & 0.02 & 0.891 & 0.00 \\
\hline
\end{tabular}

T100 - performance time for the 100-m distance, SF - stroke frequency, SL - stroke length, SI - stroke index, LAmax - maximum blood lactate concentration, tLAmax - time to reach LAmax

${ }^{*} p<0.05$ between the 2 genders

Table 3. Mean $\pm S D$ values, $F$ results, $p$ values, and effect sizes $\left(\eta^{2}\right)$ for T100, SF, SL, SI, LAmax and tLAmax in both age categories

\begin{tabular}{|c|c|c|c|c|c|c|c|}
\hline \multirow{2}{*}{ Variables } & \multicolumn{2}{|c|}{ 30-39 years } & \multicolumn{2}{|c|}{ 40-49 years } & \multirow{2}{*}{$F_{1,55}$} & \multirow{2}{*}{$p$ value } & \multirow{2}{*}{$\eta^{2}$} \\
\hline & Mean & $S D$ & Mean & $S D$ & & & \\
\hline T100 (s) & 114.33 & 27.09 & 114.59 & 19.68 & 0.03 & 0.858 & 0.00 \\
\hline SF $\left(\right.$ cycle $\left.\cdot \min ^{-1}\right)$ & 28.18 & 4.35 & 31.08 & 4.99 & 6.42 & $0.014^{*}$ & 0.10 \\
\hline $\mathrm{SL}\left(\mathrm{m} \cdot \mathrm{cycle}^{-1}\right)$ & 1.97 & 0.38 & 1.75 & 0.28 & 5.71 & $0.020^{*}$ & 0.09 \\
\hline SI $\left[\mathrm{m}^{2} \cdot(\text { cycle } \cdot \mathrm{s})^{-1}\right]$ & 1.87 & 0.72 & 1.61 & 0.59 & 2.14 & 0.149 & 0.03 \\
\hline $\operatorname{LAmax}\left(\mathrm{mmol} \cdot \mathrm{l}^{-1}\right)$ & 10.64 & 3.45 & 10.33 & 3.67 & 0.20 & 0.658 & 0.00 \\
\hline tLAmax (s) & 287.44 & 152.56 & 273.30 & 90.38 & 0.09 & 0.764 & 0.00 \\
\hline
\end{tabular}

T100 - performance time for the 100-m distance, SF - stroke frequency, SL - stroke length, SI - stroke index, LAmax - maximum blood lactate concentration, tLAmax - time to reach LAmax

${ }^{*} p<0.05$ between the 2 age categories 
$F_{1,55}=4.33, \eta^{2}=0.073$ [medium effect], $p=0.05$ ). No interaction was observed between the variables $\left(F_{1,55}=\right.$ $0.89, p<0.767$ ).

The results for the whole sample showed that all swimmers managed to swim at $95 \pm 6.3 \%$ of their HRmax.

\section{Discussion}

The purpose of the present study was to analyse the physiological responses, mechanical characteristics, and performance of males and females of 30-39 and 40-49 years of age. Previous research involved measurements during national or international swimming events. The participants of the present study could not be compared with elite master swimmers and can be perfectly described as fitness swimmers [2]. The training goals for the participants in the present study included physical activity, recreation, and occasional competition in master swimming events. To the best of our knowledge, this is the first study referring to master swimmers with these specific characteristics, who, according to Lucero and Bleul-Gohlke [2], represent $70 \%$ of the master swimmers community. For this reason, the values obtained in the present study are not comparable with those of similar research [6, 18] but are closer to those observed by Ferreira et al. [7] owing to the same ability level of the subjects.

Regarding HRpeak, the participants performed in a near-maximum intensity, at $95 \pm 6.3 \%$ of the estimated heart rate as calculated with the equation of Tanaka et al. [21]. Considering the fact that this result was not represented by elite swimmers, we can assume that this is acceptable for fitness swimmers.

The results of LAmax for males and females did not change with ageing. Therefore, it is possible to conclude that LAmax can be maintained despite ageing in healthy men and women. According to Benelli et al. [18], it is no longer certain that LAmax is reduced with ageing but it depends on experience and training. It is possible to maintain LAmax over years through highintensity training [6]. The glycolytic mechanism and therefore LAmax depend on the muscle mass involved in the exercise [18, 24]. The non-statistically significant results of the present study are likely due to the maintenance of muscle mass in spite of ageing [25].

Ageing refers to a reduction in muscle mass, as well as in the number and size of muscle fibres type II [4], yet many master athletes adopt high-intensity parts in their training program that recruits muscle fibres type II. High-intensity training is able to maintain or delay the reduction in the size and distribu- tion of muscle fibres of adult athletes as is with younger ones [6, 25]. At the same time, high-volume training can maintain muscle mass [26]. As described in the methods section, the participants of the present study followed a structured training program 3 times per week for more than 2 years so it is possible that they maintained their muscle mass.

Regarding gender, significantly lower values were observed for females compared with males. These results are consistent with the studies by Benelli et al. [18] and Ferreira et al. [7]. The glycolytic metabolism depends on muscle mass; therefore, higher lactic values were observed for males because of the greater muscle mass that they might have [15]. The analysis of tLAmax revealed that gender and age did not affect that variable.

Furthermore, the aim of the present study was to detect any differences in performance. Some previous research supports the reduction of performance with ageing [8] while others claim that there is an ability to maintain it through high-intensity and high-volume training [7]. In the present study, non-significant differences were observed with ageing. Performance time stayed stable through ageing probably because of training and the same swimming experience through each age category. With regard to gender, performance time values were lower for the whole sample of males compared with females.

Muscle strength and the ability to produce powerful and effective arm strokes in water are strongly connected to SF and SL [27]. Significantly higher values were observed for SF, SL, and SI in males, indicating their higher strength levels compared with females. As a result, we can claim that males have greater muscle strength than females, resulting in lower performance times and higher LAmax values [15].

Independent of gender, the 30-39 years age category had significantly higher values for SL and lower SF results, indicating that these swimmers can produce stronger arm strokes than those in the 40-49 years age category. Thus, we can conclude that there might be the beginning of a minor decrement in muscle strength with ageing that did not affect performance or lactate. Wider age category investigation could present more accurate results, probably indicating that training for older age categories should focus on maintenance of swimming stroke mechanics through strength training.

The measurements of the present study are able to verify the efficiency of a swimming training program and conclude possible necessities such as dry land training or better control of high-intensity and high-volume training. Furthermore, such tests offer 
a health check for the master athlete. These considerations are fundamental for master athletes intending future participation in competitions but also for recreational swimmers seeking healthy exercise conditions. The results of the present study state the need to focus on technique and the fact that coaches should expect different results for females compared with males.

Nevertheless, some limitations should be mentioned, such as the low sample size, age range, and variety of swimming training distance. However, this is the first study that reports the effects of LAmax, swimming stroke mechanics, and performance in these age groups and between genders among fitness level master swimmers. Further research should focus on a wider range of age categories, distances, and compared variables, such as energetics and other physiological data.

\section{Conclusions}

The present data conclude that males and females aged 30-39 years compared with those aged 40-49 years are able to maintain all examined variables through a structured swimming training. Excluding the variable of gender, a minor decrement in mechanics as a result of ageing is observed. Better values were noted for males compared with females. Coaches should know that lower level master swimmers are able to maintain the examined variables with a possible minor decrement in mechanics, and consider the fact that males are better than females in 100-m freestyle.

\section{Acknowledgements}

The authors would like to thank all the swimmers and their coaches who participated in this study.

\section{Disclosure statement}

No author has any financial interest or received any financial benefit from this research.

\section{Conflict of interest}

The authors state no conflict of interest.

\section{References}

1. Erickson SR, Guthrie SK. Health status of USMS swimmers compared with a representative sample of the general population. Int J Aquat Res Educ. 2012;6(3): 226-234; doi: 10.25035/ijare.06.03.07.

2. Lucero B, Bleul-Gohlke C. Masters swimming - a manual. Oxford: Meyer \& Meyer Sport; 2006.

3. Niccoli T, Partridge L. Ageing as a risk factor for disease. Curr Biol. 2012;22(17):R741-R752; doi: 10.1016/j.cub. 2012.07.024.
4. Wilkinson DJ, Piasecki M, Atherton PJ. The age-related loss of skeletal muscle mass and function: measurement and physiology of muscle fibre atrophy and muscle fibre loss in humans. Ageing Res Rev. 2018;47:123-132; doi: 10.1016/j.arr.2018.07.005.

5. Yazdanyar A, Newman AB. The burden of cardiovascular disease in the elderly: morbidity, mortality, and costs. Clin Geriatr Med. 2009;25(4):563-577; doi: 10.1016/j.cger.2009.07.007.

6. Reaburn PRJ, Mackinnon LT. Blood lactate responses in older swimmers during active and passive recovery following maximal sprint swimming. Eur J Appl Physiol Occup Physiol. 1990;61(3-4):246-250; doi: 10.1007/BF00357607.

7. Ferreira MI, Barbosa TM, Neiva HP, Vilaça-Alves J, Costa MJ, Marinho DA. Changes of the energetic profile in masters' swimmers over a season. J Sports Med Phys Fitness. 2015;55(12):1509-1516.

8. Tanaka H, Seals DR. Age and gender interactions in physiological functional capacity: insight from swimming performance. J Appl Physiol. 1997;82(3):846-851; doi: 10.1152/jappl.1997.82.3.846.

9. Donato AJ, Tench K, Glueck DH, Seals DR, Eskurza I, Tanaka H. Declines in physiological functional capacity with age: a longitudinal study in peak swimming performance. J Appl Physiol. 2003;94(2):764-769; doi: 10.1152/japplphysiol.00438.2002.

10. Gatta G, Benelli P, Ditrolio M. The decline of swimming performance with advancing age: a cross-sectional study. J Strength Cond Res. 2006;20(4):932-938; doi: 10.1519/R-18845.1.

11. Fair RC. Estimated age effects in athletic events and chess. Exp Aging Res. 2007;33(1):37-57; doi: 10.1080/ 03610730601006305.

12. Pugliese L, Porcelli S, Bonato M, Pavei G, La Torre A, Maggioni MA, et al. Effects of manipulating volume and intensity training in masters swimmers. Int J Sports Physiol Perform. 2015;10(7):907-912; doi: 10.1123/ ijspp.2014-0171.

13. Espada MC, Costa MJ, Costa AM, Silva AJ, Barbosa TM, Pereira AF. Relationship between performance, dryland power and kinematics in master swimmers. Acta Bioeng Biomech. 2016;18(2):145-151; doi: 10.5277/ ABB-00223-2014-02.

14. Ferreira MI, Barbosa TM, Costa MJ, Neiva HP, VilaçaAlves J, Marinho DA. Effects of swim training on energetic and performance in women masters' swimmers. J Hum Sport Exerc. 2016;11(1):99-106; doi: 10.14198/ jhse.2016.111.08.

15. Reaburn P, Dascombe B. Anaerobic performance in masters athletes. Eur Rev Aging Phys Act. 2009;6(1): 39-53; doi: 10.1007/s11556-008-0041-6.

16. Ferreira MI, Barbosa TM, Neiva HP, Marta CC, Costa MJ, Marinho DA. Effect of gender, energetics, and biomechanics on swimming masters performance. J Strength Cond Res. 2015;29(7):1948-1955; doi: 10.1519/JSC. 0000000000000848. 
17. Favaro OR, Lima FT. Influence of the age in the performance, stroke rate and stroke length in masters male swimmers of the 50 meters freestyle [in Portuguese]. R Bras Ci e Mov. 2005;13(2):7-15.

18. Benelli P, Ditroilo M, Forte R, De Vito G, Stocchi V. Assessment of post-competition peak blood lactate in male and female master swimmers aged 40-79 years and its relationship with swimming performance. Eur J Appl Physiol. 2007;99(6):685-693; doi: 10.1007/ s00421-006-0334-2.

19. Craig AB Jr, Skehan PL, Pawelczyk JA, Boomer WL. Velocity, stroke rate, and distance per stroke during elite swimming competition. Med Sci Sports Exerc. 1985; 17(6):625-634; doi: 10.1249/00005768-19851200000001.

20. Costill D, Kovaleski J, Porter D, Kirwan J, Fielding R, King D. Energy expenditure during front crawl swimming: predicting success in middle-distance events. Int J Sports Med. 1985;6(5):266-270; doi: 10.1055/s2008-1025849.

21. Tanaka H, Monahan KD, Seals DR. Age-predicted maximal heart rate revisited. J Am Coll Cardiol. 2001; 37(1):153-156; doi: 10.1016/S0735-1097(00)01054-8.

22. Di Prampero PE. Energetics of muscular exercise. Rev Physiol Biochem Pharmacol. 1981;89:143-222; doi: 10.1007/BFb0035266.

23. Cohen J. Statistical power analysis for the behavioral sciences. New York: Lawrence Erlbaum Associates; 1988.

24. Van Hall G. Lactate kinetics in human tissues at rest and during exercise. Acta Physiol. 2010;199(4):499508; doi: 10.1111/j.1748-1716.2010.02122.x.

25. Aagaard P, Magnusson PS, Larsson B, Kjær M, Krustrup P. Mechanical muscle function, morphology, and fiber type in lifelong trained elderly. Med Sci Sports Exerc. 2007;39(11):1989-1996; doi: 10.1249/mss.0b013e $31814 \mathrm{fb} 402$.

26. Abe T, Kojima K, Stager JM. Skeletal muscle mass and muscular function in master swimmers is related to training distance. Rejuvenation Res. 2014;17(5):415421; doi: 10.1089/rej.2014.1563.

27. Ferreira MI, Barbosa TM, Costa MJ, Neiva HP, Marinho DA. Energetics, biomechanics, and performance in masters' swimmers: a systematic review. J Strength Cond Res. 2016;30(7):2069-2081; doi: 10.1519/ jsc.0000000000001279. 